\section{Delivery of care}

I must say that I was delighted to read the letter They are called dentists from Peter Small in the summer 2008 issue of Vital, highlighting parameters for an Oral Health Review, aka a 'dental examination'.

These comprehensive procedures are almost exactly similar to those carried out in my private practice over many years, prior to formulating treatment (or not) recommendations for a patient, especially on a first visit. Firstly I would sit with the patient in a pretreatment room environment and explain amongst other things that after an hour or so we would have an idea of what their status was and would make outline recommendations which may also mean further investigations and additional visit/s to define exactly their specific needs to treat for the long term.

There is no doubt that I would be uncomfortable with anything less, but an hour in private practice is charged to the patient and is viable. What pray happens in the NHS? Bankruptcy looms if anyone spent an hour plus on an initial patient assessment visit does it not? Does this beg the question as to whether what is delivered to patients under the umbrella of the NHS is compromise and expediency? Why is the profession not more vocal on this?

Further, in the context of DCP training mentioned, the GDC profile for a clinical dental technicians training programme is not far short in content in some areas of that for dentists, with supposed ability to use radiography, recognise soft tissue pathology, degrees of periodontal breakdown and whole patient status etc which may be a little worrying if this is not structured appropriately.

Conversely, there is so much that can and should be done by therapists (orthodontic, restorative, prosthodontic and periodontal) that can transform the delivery of care to patients. The role of the dentist vis-à-vis the therapist needs some overdue management and application in this context.

\section{Dr Keith Marshall, by email}

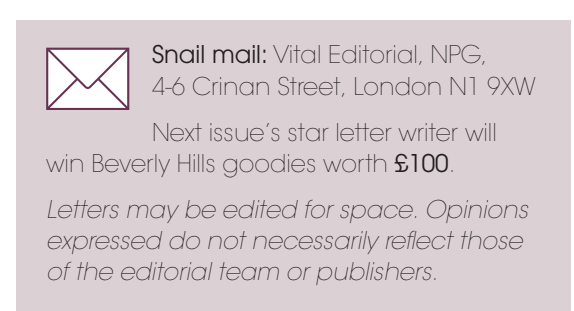

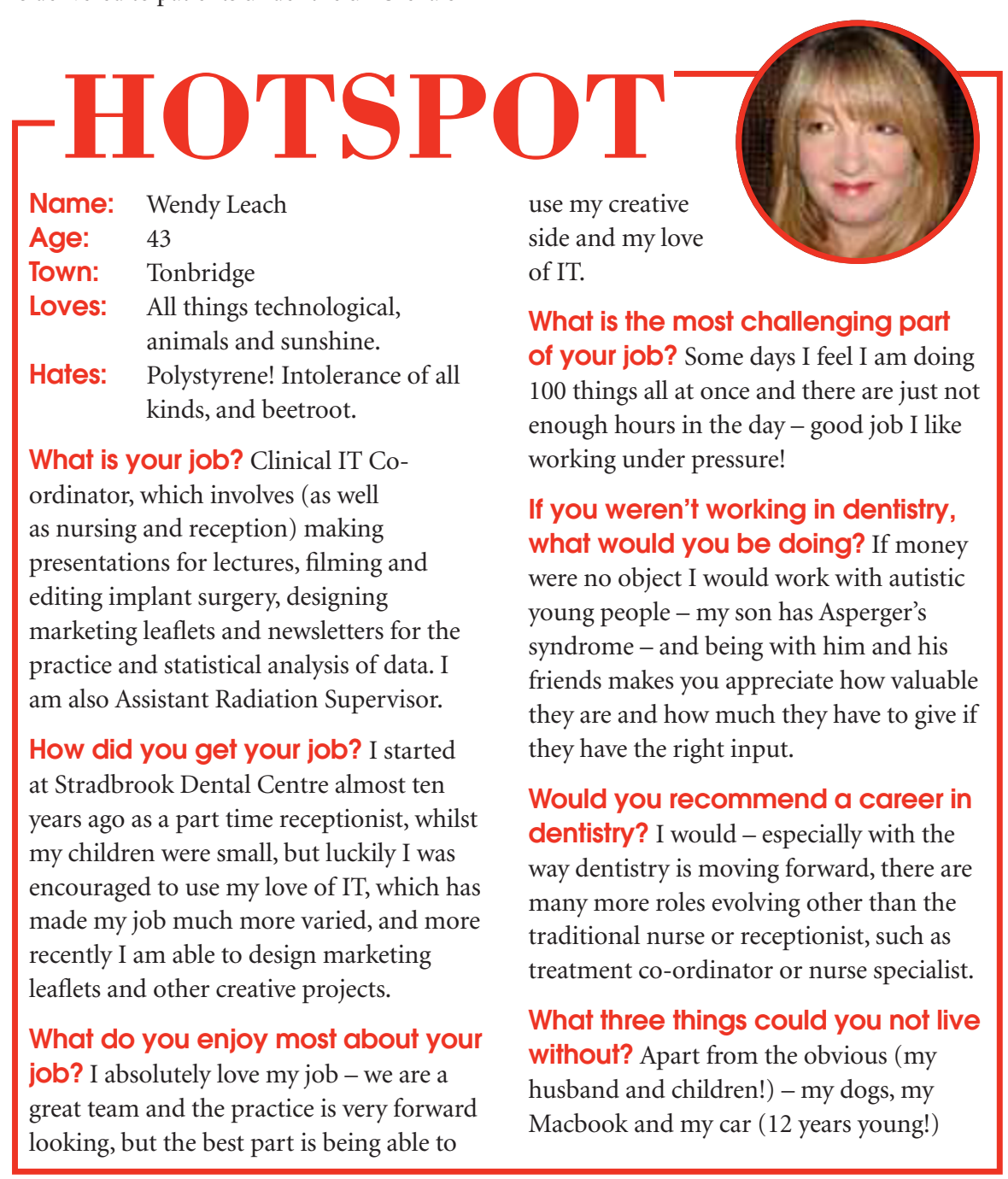

